\title{
Sexo, género y ropas
}

\section{Leite, Jorge Jr}

Resumen:

Las ropas y adornos corporales han sido siempre uno de los signos más importantes de la representación del estatus social de las personas en determinada época y/o cultura. En nuestra sociedad, "género, cuerpo y vestimenta" están íntimamente ligados, contribuyendo a delimitar jerarquías, niveles de poder e incluso posibilidades de cambio. En ese sentido, el argumento principal de este artículo es que, si bien hasta el final del siglo XVIII y el inicio de la modernidad, hombres y mujeres eran reconocidos socialmente principalmente por su función y posición social y, consecuentemente, por las ropas adecuadas a estas

Cuadernos del Centro de Estudios de Diseño y Comunicación №76

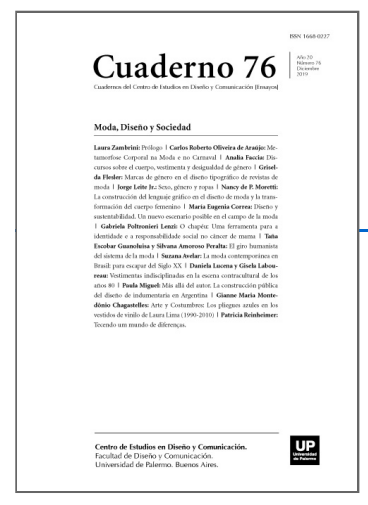

ISSN: 1668-0227

Moda, Diseño y

Sociedad

Año XX, Diciembre 2019, Buenos Aires, Argentina | 242 páginas

descargar PDF ver índice de la publicación

Ver todos los libros de la publicación

compartir en Facebook

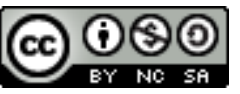
Esta obra está bajo una Licencia Creative Commons Atribución-NoComercialCompartirlgual 4.0 Internacional funciones y posición; es durante el siglo XX que el foco de este reconocimiento social se consolida en el cuerpo fisiológico, al tiempo que la moda refuerza y desdibuja este mismo reconocimiento.

Palabras clave: Género - Cuerpo - Ropas - Medicina - Cabello

(*) Profesor de Sociología de la Universidade Federal de São Carlos - Brasil. Cuenta con la investigación sobre género, sexualidad, cuerpo y la risa. Es autor de los libros Das maravilhas e prodígios sexuais - a pornografia ‘bizarra' como entretenimento (São Paulo, ed. Annablume, 2006) y Nossos corpos também mudam - a invenção das categorias 'travesti' e transexual' no discurso científico (São Paulo, ed. Annablume, 2011).

Un sexo y dos géneros

"A pesar que las mujeres vengan incorporando porsiglos elementos del vestuario masculino, el gradode confusión de esas colecciones es típico del períodocontemporáneo." (Crane, 2006:319).

De acuerdo con Thomas Laqueur (2001), desde la Antigüedad hasta el siglo XVIII, dentro de aquello que se convino llamar bien la "cultura occidental", reinaba la idea de que existía sólo un sexo fisiológico con dos 
géneros jerarquizados. Este sexo, o aparato genital, era visto como el mismo para el hombre y para la mujer, radicando su diferencia anatómica en el hecho de que estuviera hacia fuera o hacia dentro del cuerpo humano. Explico mejor: si durante los nueve meses de embarazo una madre tuviera, dentro de sí, el suficiente "calor vital" (y este calor no estaba solamente asociado a la temperatura física, sino también al desarrollo espiritual y adecuación a las normas sociales), el feto se desarrollaría al máximo, sus genitales se volverían hacia fuera de su cuerpo durante su formación y nacería un niño. Si la mujer no tuviese el calor suficiente, el feto no se desarrollaría completamente, los genitales se mantendrían dentro de su cuerpo y nacería una niña. De esta forma, el sexo, aquí entendido como aparato genital, era uno solo para hembras y machos, radicando la diferencia entre hombres y mujeres en el hecho de que los genitales estuvieran dentro del organismo (mujeres) o fuera (hombres). De este modo, predominaba la noción de que sólo existía un sexo con dos géneros jerarquizados: la mujer era un hombre incompleto, un "macho fallido", un ser menos desarrollado anatómica y espiritualmente. Según Laqueur:

Ser hombre o mujer era mantener una posición social, un lugar en la sociedad, asumir un papel cultural, no ser orgánicamente uno u otro de dos sexos inconmensurables. En otras palabras, el sexo antes del siglo XVII era todavía una categoría sociológica y no ontológica. (2001, p. 19)

De esta forma, los genitales no eran el foco de reconocimiento último o principal de lo que es ser hombre o mujer, inclusive porque se creía que, aún en adultos, el sexo podría cambiar (sea por los extraños caprichos de la naturaleza, por la resolución implacable del destino o también como consecuencia de un castigo enviado por el dios cristiano): las mujeres podría tornarse hombres, con el consecuente desplazamiento de sus genitales hacia fuera del cuerpo, y los hombres podrían afeminarse hasta el punto que sus penes y testículos migrasen cuerpo adentro, formando el canal de la vagina y los ovarios (Laquer, 2001). En esta lógica, el sexo no era un indicador seguro o definitivo de quien podría ser reconocido como hombre o mujer. Por eso, otros identificadores sociales eran necesarios para delimitar posiciones sociales, jerarquías y, principalmente, la distribución de prestigio y poder.

La ropa como expresión del alma (y el alma como justificación de la posición social)

Uno de los signos más antiguos, comunes y persistentes de clasificación social son las ropas y los adornos corporales. Históricamente, la vestimenta y sus adornos han funcionado como una expresión clara de pertenencia (o exclusión) a etnias, clases sociales y géneros, entre otros identificadores. Justamente por eso, la división entre ropas femeninas y masculinas -que todavía se hace presente se manera tan acentuada- era esencial para la organización social en Occidente (Crane, 2006). En la Antigüedad, eso queda claro en el ejemplo de Deuteronomio (22:5), en el Segundo Libro de Leyes de la Biblia: "La mujer no vestirá ropa de hombre, ni el hombre se pondrá ropa de mujer; porque cualquiera que hace esto es abominación al SEÑOR tu Dios". La abominación aquí es la idea de intercambio de papeles sociales y, consecuentemente, de intercambio de poder entre aquellos que serían considerados los únicos aptos y elegidos para comandar (hombres) y aquellos que deberían obedecer (mujeres). De acuerdo con la cosmogonía judeocristiana, esto sería una completa inversión espiritual y un verdadero desorden cósmico. Usar vestimentas consideradas típicas de un género, siendo comprendido como perteneciente al otro, podría ser visto como un tipo de agresión social y espiritual que podría generar catástrofes y castigos, ya que el orden esperado y mantenido por tales culturas "tradicionales" quedaría debilitado. 
Esta noción sólo comienza a ser lentamente cuestionada en el llamado Renacimiento, como podemos ver en estos dos ejemplos situados en los extremos de la Edad Moderna: en el siglo XVI, el personaje Hamlet, de Shakespeare, dice irritado a Ofelia: "También he oído hablar, y mucho, de vuestros afeites. La naturaleza os dio una cara, y vosotras os fabricáis otra distinta. Andáis dando saltitos, os contorneáis, habláis ceceando, y motejáis a todo ser viviente, haciendo pasar vuestra liviandad por candidez" (Shakespeare, 2010, p. 52). Y luego en el siglo XVIII, encontramos la frase del poeta y filósofo iluminista alemán Gotthold Ephraim Lessing: "La mujer que piensa da tanta repugnancia como el hombre que se pinta" (en Oaxaca, 2006, p. 24).

Nos damos cuenta que, aún en ese período, tanto la alteración estética de elementos vistos como "naturales" (en el caso del personaje Hamlet), como una antigua incomodidad agresiva en el intercambio de ropas, adornos o funciones entre hombres y mujeres (en el caso del filósofo) siguen presentes. Pero fue sólo a partir del final del siglo XVIII, o sea, en la específica modernidad europea1 que, junto a la transformación política, económica, cultural, social, tecnológica y principalmente epistemológica, surge nuestra actual concepción de dos aparatos genitales (sexos) distintos y complementarios, cada uno con un género específico asociado: pene y testículos = hombre/masculino, y vagina y ovarios = mujer/femenino. De esta forma, con el nuevo orden social que surge a partir de la modernidad, una nueva concepción de cuerpo también se hizo necesaria. Aún más, siguiendo a Laqueur: "El trabajo cultural que en el modelo de una sola carne fuera hecho por el género, pasaba ahora para el sexo" (Laquer, 2001, p. 191).

Aunque este cambio conceptual sobre sexo y género tiene sus raíces en el Renacimiento europeo, fue solamente en la segunda mitad del siglo XIX e inicio del XX, cuando se consolidó en la medicina, junto a todas las transformaciones sociales del período, como el surgimiento del Movimiento Feminista. Así, quisiera presentar en este artículo cómo, en el siglo XX, mientras las ropas pierden gradualmente su importancia histórica para indicar socialmente quién era hombre y quién era mujer, esa función pasa al cuerpo, más específicamente al sexo, aquí entendido como aparato genital/reproductor y substancias químicas orgánicas.

No es casual que en épocas de grandes cambios sociales, en especial relacionadas a las temáticas de la sexualidad y los roles de género, las ropas vistas como tradicionalmente masculinas o femeninas comiencen a ser usadas por los dos sexos, reforzándose el discurso conservador biologizante de que el género (ser masculino o femenino, hombre o mujer) es una característica bio-fisiológica, independiente de los valores socioculturales. Eso parece ser especialmente evidente en tres momentos históricos: el inicio del siglo XX, las décadas de 1960 y 1970 y el paso del siglo XX al siglo XXI. En este recorrido, la relación simbiótica entre cuerpo y vestimenta es constantemente evocada.

Actualmente, nuestra cultura, el cuerpo y la vestimenta, además de ser vistos de manera casi indivisible, han sido pensados constantemente como metáfora uno del otro. Más específicamente, la ropa, en varios campos del saber (religión, filosofía, medicina, sociología, entre otros) ha sido considerada como una "segunda piel", y el cuerpo fue descrito como la vestimenta (o envoltura) del alma o psique humana. Esta estrecha relación, en la cual el exterior se presenta como la materialización del interior y viceversa, en que forma y contenido son indivisibles, es también uno de los elementos que más generan tensiones y disputas sociales en el campo de la intersección entre moda, sexo y género hasta hoy día. Veamos a continuación algunos ejemplos: 
En la segunda mitad del siglo XIX y, más específicamente en el paso de este para el siglo XX, junto con el inicio de los estudios científicos modernos sobre sexo (Foucault, 1988); las discusiones sobre los límites entre el hombre y la mujer, la masculinidad y la feminidad y el debate sobre cómo demarcar estas fronteras estaban a la orden del día. En el campo médico, la intersexualidad y la homosexualidad eran concebidas como los extremos físicos y mentales de un mismo fenómeno patológico en el cual la masculinidad y la feminidad (orgánica o psíquica) estaban indebidamente mezcladas (Dreguer, 2003). En el campo político, el Movimiento Feminista evocaba la misma ansiedad, miedo e incomodidad, pues esta lucha social representaba ante todo un cuestionamiento de la naturalización de los privilegios masculinos (Crane, 2006). Fue característico de la modernidad en adelante, que en los momentos en que los valores socioculturales se vieran amenazados, la ciencia apela a la "naturaleza" y a la biología para justificar creencias y valores socialmente construidos. Es en este sentido que, en el año 1925, Carlos Lagos García, un médico cirujano argentino, especialista en casos de intersexualidad (llamados entonces hermafroditas y/o pseudo-hermafroditas) afirmaba en su libro Las deformidades de la sexualidad humana (1925) que: "del pseudo-hermafrodita externo podríamos decir que es un hombre 'vestido' anatómicamente de mujer" (Lagos García, 1925, p. 369). En este caso, ya que la ropa no era más la expresión del alma -en el sentido cósmico y religioso del término- el cuerpo pasaba a ser la vestimenta de la psique, aunque, en muchos casos, para la lógica médica heteronormativa, el género de la mente estuviese en "desacuerdo" con su vestimenta corporal.

De la misma manera, en el año 1930, el médico español Gregorio Marañón hizo un curioso análisis de la función de las cabelleras en los hombres y las mujeres en su libro La evolución de la sexualidad y los estados intersexuales. Poco después de la moda de las provocadoras flappers con sus faldas cortas, bailes atrevidos y cabellos cortos (durante los años 20), este autor afirmó que el cabello del hombre nunca pasa del hombro; que la calvicie masculina tiene "la dignidad de un verdadero carácter sexual" por su "predilección por el sexo viril"; el cabello largo de la mujer tiene como objetivo la atracción erótica y, sobre la moda de las muchachas de la época, esclarece:

Es oportuno, por lo demás, añadir, con relación al cabello corto de la mujer, que su verdadero sentido no es como se cree el de una tendencia virilista. Es cierto que la aparición de esta moda coincidió con el gran avance del feminismo durante la guerra europea y los primeros años de la post-guerra; y que encajaba dentro de un conjunto de detalles de la anatomía y de la indumentaria, reveladores de una clara intención inversiva. Pero aparte de las razones de comodidad y economía que supone para la mujer el cabello corto y que influirán seguramente en su duración, el verdadero sentido de esta mutilación sexual no es tanto la tendencia viriloide como la aspiración juvenil. (Marañón, 1930, p. 24)

Estos dos autores, en especial Marañón (que fue internacionalmente influyente en los debates del área en su época, incluso en Brasil), no están revelando verdades que fuesen descubiertas, pero sí estableciendo por la vía del discurso científico, los patrones socioculturales de la época. O sea, su argumentación es mucho más prescriptiva que descriptiva (Preciado, 2008). Según este médico: "Pero es asimismo necesario recalcar que las aspiraciones panvirilistas de la mujer del tipo 'sufragista' -igualdad absoluta en la actividad de los sexospugnan abiertamente con las leyes eternas e inmutables de la naturaleza" (Marañón, 1930, p. 176). Así, tampoco es casual que este médico español también haya afirmado categóricamente que los hombres no lloran, pues esto sería fisiológicamente imposible. Si un hombre llorara, significaría que él no es completamente -física o psíquicamente- hombre (Marañón, 1930, p. 171). 
En la segunda mitad del siglo XX, se desarrolla el movimiento social "contracultura", centrado en la juventud y que tenía como una de sus características la estética andrógina, siendo su influencia en el cambio de los valores y comportamientos sexuales conocida como "revolución sexual". De esta forma, surgen variadas manifestaciones culturales y artistas portadores de una estética que mezclaba intencionalmente elementos considerados masculinos y femeninos. En esta línea, se puede citar al cantante inglés David Bowie, a la banda brasileña Secos e Molhados y al grupo de danza y música, también brasileño, Dzi Croquetes. Pero no era todo libertario o transgresor. Por ejemplo, en el ámbito de las ciencias sociales, el sociólogo y psicólogo estadounidense Charles E. Winick, escribió The new people - dessexualization in american life. En ese libro, editado en el año 1969, el autor analizó con recelo la pérdida de los valores, de las estéticas y los comportamientos notoriamente distintos entre hombres y mujeres, siendo esto, en su visión, el mayor síntoma de la decadencia de la cultura norteamericana. La creciente indiferenciación entre hombres y mujeres o, siguiendo la expresión usada, la "des-sexualización en la vida americana", llevaría a la ruina futura del pueblo estadounidense. Reflexionando sobre los temas más variados tales como: el ocaso del amor romántico; la introducción de bailes latinos en los clubes estadounidenses; el surgimiento del rock'n roll; la invocación de una nueva sensibilidad en la música, en el teatro y en las artes en general; la crianza de animales domésticos (con la preferencia cada vez mayor de los americanos por los gatos en vez de los perros); los nombres dados a los niños; los juegos infantiles; la arquitectura; la alimentación y la moda de las dietas; los tipos de bebidas alcohólicas consumidos por los jóvenes; la ruptura de las normas de comportamiento asociadas a los géneros como las mujeres fumando y los hombres usando perfume o el maquillaje cada vez más leve de las mujeres y los hombres leyendo novelas; el cambio en las prácticas eróticas y el uso de órganos sexualmente "neutros" como la boca y el ano durante el acto sexual (según la polarización genital que el autor trabaja); y, claro, la no diferenciación entre ropas masculinas y femeninas, todo eso para Winick era reflejo de la decadencia social en la que se estaría enterrando su país. Sobre el vestuario, el autor comentaba en varios momentos:

La más visible adaptación del vestuario masculino por las mujeres es que ellas hayan sustituido la red protectora del corsé por la libertad de los pantalones (p. 197); La ropa representa el mobiliario de la mente y los cambios transexuales del hoy deberían producir efectos profundos. Los cambios en el vestuario afectan el modelo de los automóviles y de otros productos (Winick, 1969, p. 229).

Y:

Actualmente, la forma preferida, por hombres y mujeres, es holgado e informe, expresando y acentuando nuestra indefinición de lo masculino y de lo femenino. El vestuario profundiza aún más el conflicto interno y la confusión de cada siglo para desempeñar su papel (p. 230); En las dos últimas décadas, período en que la indumentaria permitió una expresión más completa de la individualidad y también se tornó más libre y “divertida”, también contribuyó a nuestra renuncia a lo masculino y lo femenino (Winick, 1969, p. 235).

Es curioso notar como en este libro, no sólo las ropas con sus nuevos modelos, colores y tejidos que pueden ser usados tanto por hombres como por mujeres, representan un desorden social que debe ser advertido y evitado, sino que también, al igual que el médico español de la década de los años '30, el autor dedicaba una sustancial parte del libro a discutir los cambios en los colores y cortes de cabello de hombres y mujeres, concluyendo: "Proyectamos nuestra incertidumbre en relación con el futuro ambiguo en las siluetas del vestuario. Los tiempos decretan nuestra certidumbre, la certidumbre influencia a la moralidad, la moralidad afecta a las formas y las formas conducen a las modas" (Winick, 1969, p. 229). 
Tanto Marañon como Winick, aunque no intencionalmente, dejan claro cuánto la vestimenta y el corte de cabello, o sea, la moda, expresa valores sociales y culturales que varían de época en época y de grupo en grupo, no teniendo ella nada que ver con la manifestación de "esencias humanas" universales y atemporales. Una vez más, cuando las ropas y el cabello no sirven más de guía confiable para la distinción entre hombres y mujeres, el cuerpo viene a ocupar este lugar imaginario de un puerto seguro e incuestionable. No es casual que, también para el sociólogo, la argumentación en su libro lleva al miedo apocalíptico de que todas las transformaciones socioculturales causasen la degeneración biofisiológica de los norteamericanos:

Los hombros femeninos se están volviendo más anchos en relación con sus caderas; y su físico, bajo otros aspectos, está adquiriendo proporciones más masculinas (...) Tales cambios contribuyen a la disminución del dimorfismo sexual, y ocurren incluso cuando la disminución de la edad de aparición de la primera menstruación proporcione menos tiempo para que el crecimiento tenga lugar (Winick, 1969, p. 105).

Lo importante de estos ejemplos es mostrar cómo la moda -expresada tanto en el vestuario, como en los estilos de cabello- aún es un referencial relevante de género que, al ser cuestionado, transgredido o parodiado, sea por vertientes político culturales, por los medios o por la industria fashion, provoca serias reacciones de incomodidad e insatisfacción, reafirmando que la asociación entre ropas y género todavía tiene una fuerte carga social.

\section{“¿Con qué ropa (o cuerpo) voy?”}

En el inicio del siglo XXI, dentro del nuevo régimen "postindustrial, global y mediático" (Preciado, 2008, p. 32) surgido a partir de la segunda mitad del siglo XX, cuando el movimiento social organizado LGBT y de Mujeres, entre otros grupos históricamente discriminados, conquistara más espacio y derechos en gran parte de los países occidentales democráticos. Mientras una tendencia expresiva de la moda se ha vuelto cíclicamente hacia lo visual andrógino y la temática de género es ampliamente debatida por varios sectores de la sociedad; el discurso biologizante también se acentúa y diluye, saliendo de la genitalidad y centrándose en los genes y las hormonas. En ese sentido, el filósofo español Paul B. Preciado llama a ese régimen 'fármaco-pornográfico', “(...) tomando como referencia los procesos de gobierno biomolecular (fármaco-) y semiótico-técnico) (-porno) de la subjetividad sexual" (Preciado, 2008, p. 32). Y: "El éxito de la tecno-ciencia contemporánea es transformar nuestra depresión en Prozac, nuestra masculinidad en testosterona, nuestra erección en Viagra, nuestra fertilidad/esterilidad en píldora, nuestro sida en triterapia" (Preciado, 2008, p. 33).

Está claro que la moda, como industria y mercado pero también como valor estéticopolítico, no pretende abandonar la distinción femenino/masculino. Esta es una separación todavía estructurante de nuestra epistemología y de nuestro sistema económico. Tal como explica Diana Crane (2006, p. 47):

Las ropas de la moda son usadas para hacer una declaración sobre clase e identidades sociales, pero sus mensajes principales se refieren a las maneras por las cuales mujeres y hombres consideran sus roles de género, o cómo se espera que ellos los perciban.

Y esto puede ser considerado válido aún para nuestra fase actual del siglo XXI. La moda para hombres y para mujeres posee mercados propios que no demuestran la menor señal de agotamiento. De esta forma, la industria de la moda como un todo, también invierte en nuevos frentes: las modas unisex, transgéneras, y también la moda "para hombres" y "para mujeres" que intencionalmente usa elementos de los dos géneros para transgredir 
valores sexuales. En este sentido, no es coincidencia que cuánto más las ropas y la moda se tornan un campo legítimo, tanto para reflejar conflictos culturales como para experimentar cambios sociales, la dilución de fronteras entre vestuario, cortes de cabello y adornos vistos tradicionalmente como masculinos y femeninos, no sólo generan ansiedad en los sectores más conservadores, sino que además provoca reacciones más amplias, inclusive en los campos del saber. Al tiempo que, la separación rígida de los límites entre moda/apariencia masculina y femenina pierde su solidez histórica, las ciencias biomédicas buscan en la estructura bio-fisiológica, con toda su micro-complejidad, una base de justificación para la separación entre hombres y mujeres.

Notas

1. Concuerdo con los autores postcoloniales y de-coloniales en que la "modernidad" no es única, lineal o uniforme, y en que la modernidad europea surgió como consecuencia directa del proceso de colonización, tanto de las américas como de África y Asia (Mellino, 2008; Pelúcio, 2012).

\section{Bibliografía}

Crane, D. (2006). A moda e seu papel social. São Paulo: SENAC.

Dreger, A. D. (2003). Hermaphrodites and the medical invention of sex. Cambridge: Harvard University Press.

Foucault, M. (1988). História da sexualidade I - A vontade de saber. Rio de Janeiro: Graal.

García, C. L. (1925). Las deformidades de la sexualidad humana. Buenos Aires: "El Ateneo" librería científica y literária. Jaramillo, Ma. Del R. O. (2006). Como se construye la sexualidad a través del lenguage in Revista Terapia Sexual, São Paulo: Instituto Paulista de Sexualidade, Volume IX - № 1, janeiro a junho de 2006.

Laqueur, T. (2001). Inventando o sexo. Rio de Janeiro: Relume Dumará.

Marañon, G. (1930). La evolución de la sexualidad y los estados intersexuales. Madrid: Javier Morata Editor.

Mellino, M. (2008). La crítica poscolonial. Buenos Aires: Paidós.

Pelúcio, L. (2012). Subalterno quem, cara pálida? Apontamentos às margens sobre póscolonialismos, feminismos e estudos queer. Contemporânea: Revista de Sociologia da UFSCar, 2(2):395-418. Disponível em: http://www.contemporanea.ufscar.br/index.php/ contemporanea/article/view/89/54. Acesso em: 21/02/2013.

Preciado, B. (2008). Texto Yonqui. Madrid: Editorial Espasa Calpe.

Shakespeare, W. (1978). Hamlet, príncipe da Dinamarca. São Paulo: Abril Cultural.

Shakespeare, W. (1998a). Otelo. Romeo y Julieta. Chile: Editorial Andrés Bello.

Shakespeare, W. (2010b). Hamlet, príncipe de Dinamarca. Colombia: Editorial Universidad de Antioquia.

Winick, C. E. (1969). Unissexo. São Paulo: Perspectiva. 
Abstract: Garments have been one of the most important signs of social status. In our society, "gender, body and clothing" are intimately linked to define hierarchies, levels of power and even possibilities for social change. In this sense, the main argument of this article is that, although until the end of the 18th century and the beginning of modernity, men and women were socially recognized mainly for their function and social position and, consequently, for the right clothes to wear. During the 20th century, the focus of this social recognition was consolidated in the physiological body, while fashion reinforced this same recognition.

Keywords: Gender - Body - Garment - Medicine - Hair.

Resumo: Roupas e adornos corporais sempre foram as sinais mais importantes da representação do status social das pessoas em um determinado tempo e cultura. Em nossa sociedade, "gênero, corpo e vestuário" estão intimamente ligados com as hierarquias, poder e até possibilidades de mudança. Nesse sentido, o principal argumento deste artigo é que, embora até o final do século XVIII e o início da modernidade, homens e mulheres eram socialmente reconhecidos pela posição social e, consequentemente, pela roupa certa para vestir. Foi no século XX, que o foco desse reconhecimento social foi consolidado no corpo fisiológico, enquanto a moda reforçaba esse mesmo reconhecimento.

Palavras-chave: Gênero - Corpo - Vestuário - Medicina - Cabelo.

[Las traducciones de los abstracts fueron supervisadas por el autor de cada artículo]

Sexo, género y ropas fue publicado de la página 63 a página71 en Cuadernos del Centro de Estudios de Diseño y Comunicación $\mathrm{N}^{0} 76$ 